\section{Duodenal Diverticula and ERCP: A New Trick}

It is generally accepted that the frequency of occurrence of duodenal diverticula significantly increases with age. The prevalence of peripapillary diverticula is estimated at $10-15 \%(1)$, and it can reach $30 \%$ in the elderly $(1,2)$. The position of the papilla can be modified by the presence of the diverticulum, rendering the cannulation more difficult. When this happens, there is agreement that the success rate of endoscopic retrograde cholangiopancreatography (ERCP) is lower than that in the normal situation, although the difference is not statistically different $(1,2)$. However, once cannulation succeeds, endoscopic sphincterotomy can be carried out with a similar level of risk $(1-6)$.

We used a new technique in a patient with suspected bile duct lithiasis, whose papilla was located on the common edge of two large duodenal diverticula. Each time cannulation of the papilla was attempted, the tip of the endoscope slipped into one of the diverticula, and the papillary orifice became hidden behind the common edge of the diverticula. We therefore decided to use a duodenoscope equipped with a large channel (Olympus JF-1T100), and to introduce both the biopsy forceps (Olympus FB-21SX) and the catheter into the operating channel. The diverticulum mucosa, next to the papilla, was then trapped with the biopsy forceps; with pushing pressure being exerted on the forceps, the papilla was fixed in front of the operating channel of the duodenoscope (Figure 1, 2). Opacification of the biliary duct showed a single stone; we then performed a sphincterotomy and easily extracted the stone with a Dormia basket.

This trick is easy to perform, as a less experiencied endoscopist used it again easily in another patient in a similar situation. It only requires a duodenoscope with a large operating channel and a nurse accustomed to the manipulation of both the catheter and the forceps. We recommend this technique whenever a duodenal diverticulum prevents ERCP.

\section{References}

1. Vaira D, Dowsett JF, Hatfield ARW, et al. Is duodenal diverticulum a risk factor for sphincterotomy? Gut 1989; 30: 939-42.

2. Shemesh E, Klein E, Czerniak A, et al. Endoscopic sphincterotomy in patients with gallbladder in situ: the influence of periampullary duodenal diverticula. Surgery 1990; 107: 163-6.

3. Cotton PB, Lehman G, Vennes J, et al. Endoscopic sphincterotomy complications and their management: an attempt at consensus. Gastrointest Endosc 1991; 37: 383-93.

4. Cotton PB. Endoscopic management of bile duct stones. Gut $1984 ; 25: 587-97$.

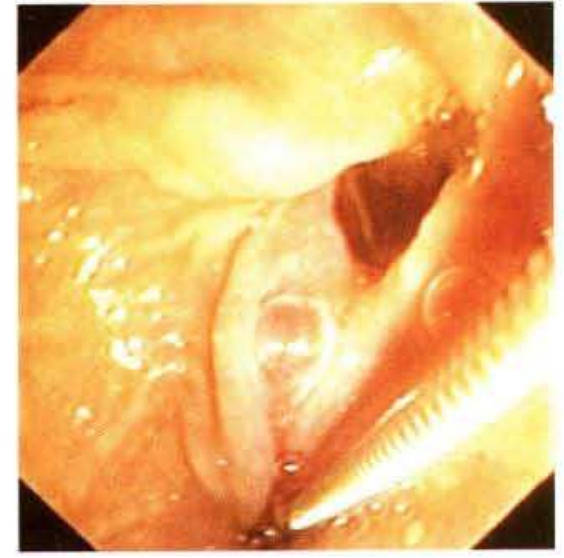

Figure 1: First, the papilla is pulled outside the diverticula with a biopsy forceps.

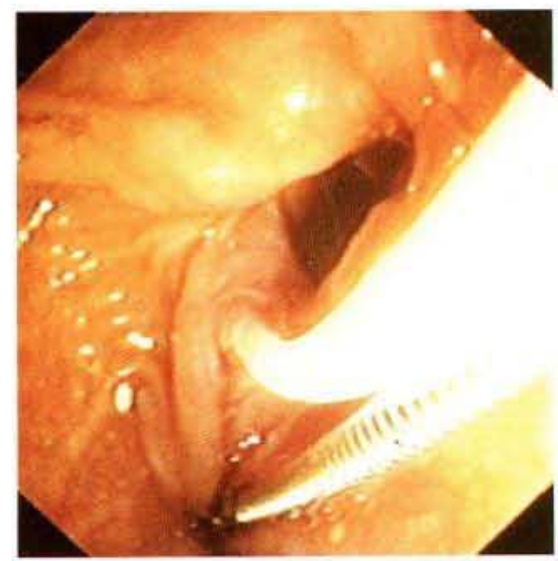

Figure 2: Once the papilla is held in tront of the operating channel of the duodenoscope, catheterization is easy

5. Dowsett JF, Vaira D, Hatfield ARW, et al. Endoscopic biliary therapy using the combined percutaneous and endoscopic technique. Gastroenterology 1989; 96: 1180-6.

6. Farkas IE, Preisich P. Endoscopic sphincterotomy in juxtapapillary diverticula. Dig Dis Sci 1986; 31: 239S.

\section{Tantau, B. Person, P. Burtin. J. Boyer}

Hepatogastroenterology Unit, Angers Hospital, Angers, France

Corresponding Author

J. Boyer, M.D.

Hepatogastroenterology Unit

Angers Hospital

49033 Angers

France

Fax: $+33-41-354119$ 